\title{
Desenvolvimento Rural dos Municípios do Estado do Pará: desigualdade e espacialidade
}

\author{
Adriano Nascimento Paixão \\ Universidade Federal do Paraiba - João Pessoa - PB - Brasil \\ ORCID: http://orcid.org/0000-0002-2717-3716 \\ Nilton Marques Oliveira \\ Universidade Federal do Tocantins - Palmas - TO - Brasil \\ ORCID: http://orcid.org/0000-0001-6485-314X \\ Marcus Vinicius Mendonça \\ Instituto Chico Mendes de Conservação da Biodiversidade - Parauapebas - PA - \\ Brasil \\ ORCID: http://orcid.org/0000-0001-5209-4385 \\ Rodolfo Alves Luz \\ Universidade Federal do Tocantins - Palmas - TO - Brasil \\ ORCID: http://orcid.org/0000-0002-6608-4898
}

\section{Resumo}

O artigo tem o objetivo de construir e analisar um índice de desenvolvimento rural para os municípios do estado do Pará. Para o cálculo do índice utilizou-se o método de análise fatorial. As variáveis utilizadas foram obtidas junto aos Censos Demográficos do IBGE (2000 e 2010), Atlas do Desenvolvimento Humano no Brasil do PNUD (2013) e Censo Agropecuário do IBGE (2006). Os resultados revelam uma prevalência de municípios com baixos índices de desenvolvimento rural no estado. A infraestrutura das áreas rurais dos municípios do interior do estado são mais precárias quanto maior é a dificuldade de acesso e o grau de isolamento destas áreas. A colonização de regiões distantes não foi acompanhada de investimentos em obras e serviços adequados ao provimento de qualidade de vida tanto de populações tradicionais quanto da população migrante que se instalou nas áreas rurais do estado.

Palavras-chave: Análise Factorial. Índice de Desenvolvimento Rural Desenvolvimento Rural. Amazônia. Desigualdade.

Rural Development of the Municipalities of the State of Pará - Brazil: inequality and spatiality

\section{Abstract}

This paper aims to calculate and to analyze a rural development index for the municipalities of Pará state, Brazil. The index was calculated by the factor analysis method. The variables used in the model were retrieved from the 2000 and 2010 population census; Human Development Atlas - UNDP (2013), and census of agriculture (2006). The results unveiled 
that most of the municipalities of Para presented low rural development index values. The greater is the isolation and the difficulty to access the areas, the worse it is the infrastructure found in those rural areas. Colonization of new areas was not followed by the implementation of services and the required infrastructure to provide life quality for both native and the migratory population that installed in the rural areas of Para state, Brazil.

Keywords: Factor Analysis. Rural Development. Amazonia. Inequality.

Desarrolo Rural de los Municipios del Estado de Para: desigualdad y espacialidad.

\section{Resumen}

El artículo tiene como objetivo construir y analizar un índice de desarrollo rural para los municipios del estado de Pará. Para calcular el índice, se utilizó el método de análisis factorial. Las variables utilizadas se obtuvieron de los Censos Demográficos del IBGE (2000 y 2010), el Atlas de Desarrollo Humano en Brasil del PNUD (2013) y el Censo Agrícola del IBGE (2006). Los resultados revelan una prevalencia de municipios con bajos índices de desarrollo rural en el estado. La infraestructura de las zonas rurales en los municipios del interior del estado es más precaria cuanto mayor es la dificultad de acceso y el grado de aislamiento de estas áreas. La colonización de regiones distantes no estuvo acompañada de inversiones en obras y servicios adecuados para proporcionar calidad de vida tanto a las poblaciones tradicionales como a la población migrante que se estableció en las zonas rurales del estado.

Palabras clave: Análisis factorial. Desarrollo Rural. Amazonia. Desigualdad

\section{Introdução}

Este artigo tem o objetivo de construir e analisar o Índice de Desenvolvimento Rural (IDR) para os municípios do estado do Pará e desta forma conhecer as diferenças locais e regionais que determinam o desenvolvimento a partir de variáveis que possam dimensionar causas, características e possíveis consequências de um desenvolvimento desigual.

De acordo com Delgado (2001), o desenvolvimento do setor agropecuário brasileiro tem passado por constantes transformações no campo. Após a segunda guerra e, principalmente entre no período de 1964 e 1980, conhecida como "modernização conservadora", foi estimulada a adoção de pacotes tecnológicos da chamada "Revolução Verde" e o aumento da produção a partir de financiamento ao latifúndio e, por outro lado, houve um aprofundamento da heterogeneidade da agricultura brasileira. Após o fim do regime militar ocorre o retorno da questão agrária ao debate político e econômico na década de 1980, assim como uma relativa estagnação industrial.

A expressão desenvolvimento rural e a melhoria do bem-estar das populações rurais mais pobres, surge na década de 1970, como resultado do processo de mudança produtiva na agricultura, sinônimo de desenvolvimento agrícola (NAVARRO, 2001).

Na década de 1990 estudiosos do tema redimensionam o significado do que é o "rural". O rural deixou de ser um espaço exclusivamente agrícola. Segundo Wanderley (2000), a crise produtivista de modernização agrícola e transformações recentes no meio rural nos países avançados apontam para a "emergência de uma nova ruralidade". Isso em razão da descentralização econômica de atividades industriais e comerciais para espaços rurais, a "paridade" econômica e social entre a 
população rural que obteve acesso tanto a bens e serviços modernos quanto a níveis de renda mais próximos aos dos habitats das cidades, o crescimento demográfico em razão da redução dos fluxos migratórios do campo para as cidades e a atração para o meio rural de outras categorias sociais.

Para Veiga (2000, 2008), não existe o desenvolvimento rural como fenômeno concreto e separado do desenvolvimento urbano. A economia rural está sempre integrada a uma cidade, e a economia regional é o contexto adequado para compreender o desenvolvimento rural. Kageyama (2004), relata que há um certo consenso sobre a definição de rural, qual seja: rural não é sinônimo de e nem tem exclusividade sobre o agrícola; o rural é multissetorial (pluriatividade) e multifuncional (funções: produtiva, ambiental, ecológica, social); as áreas rurais têm densidade populacional relativamente baixa; não há um isolamento absoluto entre os espaços rurais e as áreas urbanas.

O estado do Pará é o segundo maior estado do país com extensão territorial de 1.247.689,515 quilômetros quadrados ou 14,66\% do território nacional (Pará, 2000). De acordo com o Censo do IBGE (2010) são 7.581.051 habitantes, sendo 31,5\% residentes na zona rural. $O$ estado possui 144 municípios distribuídos em 12 regiões de integração. A política de Integração Nacional implementada na Amazônia após a década de 1970, levou o Pará a tornar-se o principal território de exploração de recursos naturais não renováveis (SILVA, 2012), com o objetivo de integração das principais áreas mineradoras à economia internacional como forma de aumentar a pauta de exportações (COSTA, 2006, 2009 e 2010). Grandes projetos como a construção da Usina Hidrelétrica de Tucuruí, a Mineração Rio do Norte, a Albrás e Alunorte e o Projeto Ferro Carajás geraram novas regiões no Estado (SANTOS, 2016).

Silva (2012) revela as mudanças de características da dinâmica regional no estado do Pará. Constatou-se que os investimentos em infraestrutura básica (rodovias, ferrovias e hidrelétricas) produziram o crescimento econômico estadual e promoveram o deslocamento da dinâmica socioeconômica estadual da mesorregião Metropolitana de Belém para outros subespaços regionais, a partir da década de 1980. Algumas cidades passaram a compartilhar com Belém a dinâmica socioeconômica estadual como Ananindeua, Barcarena, Marabá, Parauapebas, Tucuruí e Redenção. É preciso verificar quais os impactos que estas diferentes trajetórias regionais tiveram para o mundo rural do estado do Pará, tendo em vista a importância que o campo tem para a economia do estado. O uso de um Índice de Desenvolvimento Rural (IDR) é uma forma encontrada para comparar a realidade em diferentes municípios, de maneira a apontar similaridades e distorções nos processos de desenvolvimento rural.

Isto posto, este artigo está divido em cinco partes. Além desta introdução, a segunda aborda resumidamente algumas considerações sobre o desenvolvimento rural. A terceira, a metodologia, descrevendo a análise fatorial e as descrições das variáveis. Na quarta, discute-se os principais resultados e, por fim, as considerações finais sumarizam o artigo. 


\section{Desenvolvimento Rural: breve comentários}

Para Ploeg et al. (2000), o paradigma da modernização da agricultura, que dominou a teoria, as práticas e as políticas, como a principal ferramenta para elevar a renda e levar o desenvolvimento as comunidade rurais, vem sendo substituído por um novo paradigma, o do desenvolvimento rural, buscando um novo modelo para o setor agrícola, com novos objetivos, como a produção de bens públicos (paisagem), sinergias com os ecossistemas locais, a maior valorização das economias de escopo em relação às economias de escala, e a pluriatividade das famílias rurais.

Ploeg et al. (2000) consideram o desenvolvimento rural em cinco níveis: o crescente inter-relacionamento da agricultura com a sociedade, fazendo com que esta perceba que o rural pode fornecer muito mais do que alimentos e matériasprimas; uma necessidade urgente em definir um novo modelo agrícola, capaz de valorizar as sinergias e a coesão no meio rural entre atividades agrícolas e nãoagrícolas, ecossistemas locais e regionais, permitindo convivência de iniciativas e atividades diversificadas; um desenvolvimento rural capaz de redefinir as relações entre indivíduos, famílias e suas identidades, atribuindo um novo papel aos centros urbanos e a combinação de atividades multiocupacionais; um modelo que redefina o sentido de comunidade rural e as relações entre os atores locais; um desenvolvimento rural que leve em conta a necessidade de novas ações de políticas públicas e o papel das instituições.

Schneider (2004) acrescenta um sexto nível: é preciso um novo modelo que leve em consideração as múltiplas facetas ambientais, buscando garantir o uso sustentável e o manejo adequado dos recursos. Segundo Ploeg et al. (2000), o cenário complexo das instituições participantes do desenvolvimento rural torna esse processo dependente de múltiplos atores, os quais estão envolvidos em relações locais e entre as localidades e a economia global. Para os autores, o desenvolvimento é ainda multifacetado, pois se desdobra em uma grande variedade de novas atividades, como administração da paisagem, conservação da natureza, agroturismo, agricultura orgânica, produção de especialidades regionais, vendas diretas, etc.

Conforme aponta Veigam (2001), na perspectiva de expansão das capacidades individuais e melhoria dos funcionamentos, preconizado na definição de Sen (2000) sobre o desenvolvimento, os elementos fundamentais do processo de desenvolvimento rural são a valorização e o fortalecimento da agricultura familiar, a diversificação das economias dos territórios, o estímulo ao empreendedorismo local, o "empurrão" que viria do Estado para a formação de arranjos institucionais locais, além da menor desigualdade do acesso à terra e à educação, como elementos-chave para a nova estratégia de desenvolvimento rural sustentável do Brasil.

O desenvolvimento rural é visto, portanto, como um processo que envolve a dimensão econômica, dimensão sociocultural, dimensão político-institucional e dimensão ambiental (KAGEYAMA, 2004 e 2008; CONTERATO, 2008; STEGE e PARRÉ, 2011) e não apenas como um processo de crescimento econômico medido unicamente pelo produto ou renda per capita.

Indo nesta direção sobre o desenvolvimento rural, tem-se observado a elaboração do Índice de Desenvolvimento Rural (IDR) por diversos pesquisadores 
brasileiros. O índice possibilita medir aspectos de um determinado conceito, certa realidade, fenômeno ou um problema, e seu objetivo principal é "[...] traduzir de forma mensurável determinado aspecto de uma realidade dada (situação social) ou construída (ação de governo)" (STEGE e PARRÉ, 2011, p. 6).

Neste sentido, os trabalhos de Kageyama (2004 e 2008), Melo e Parré (2007), Waquil et al. (2007), Conterato (2008), Stege e Parré (2011) propõem um indicador para unidades e focos diferentes. Kageyama (2004) e Melo e Parré (2007), possuem como unidade de análise o rural municipal e elaboram um IDR para os municípios de São Paulo e Paraná, respectivamente. Waquil et al. (2007) desenvolveu um Indicador de Desenvolvimento Sustentável (IDS) para quatro territórios rurais, definidos pelo Ministério do Desenvolvimento Agrário. Kageyama (2008) elaborou um Índice de Desenvolvimento Rural (IDR) para os estados brasileiros, enquanto Stege e Parré (2011) construiu um IDR sintético para todas as microrregiões brasileiras. Silva et.al. (2017) elaboraram o Índice de Sustentabilidade dos Municípios da Amazônia (ISMA), composto por quatro dimensões, onde cada uma delas acompanha áreas diferentes do desenvolvimento dos municípios da região. O ISMA tem como objetivo estudos nos gargalos ao desenvolvimento regional. Souza (2014) propõe um índice do IDR para os municípios do Pará, a construção do indicador foi obtida a partir de quatro índices parciais considerando as dimensões populacionais, econômica, social e ambiental, nesse caso, a autora não utilizou ferramentas de estatística multivariada para a construção do IDR proposto.

Mais recentemente, Renzi (2019), apresenta a criação dos índices, um índice de desenvolvimento econômico da ruralidade e um índice de desenvolvimento econômic local para os municípios brasileiros. Lobão e Staduto (2020), criar um IDR para 449 municípios situados na Amazônia Legal para a década dos anos 2000. A construção desse IDR utilizou o método das componentes principais.

Em nível internacional, também existem algumas iniciativas no sentido de criar indicadores de desenvolvimento rural, Abreu et al. (2019) criar um IDR para um conjunto de municípios em Portugal, o IDR criado por esses autores é baseado no IDR criado por Kageyama (2008). Michalek e Zarnekow (2012), também sugerem a criação de um IDR para áreas rurais da Polônia e Eslováquia, esses autores utilizam análise fatorial e ferramentas de econometria espacial para construção de um IDR. Hashemi e Gholamreza (2017) apresentam um indicador de desenvolvimento rural sustentável para uma região do Iran.

Neste artigo elaborou-se um Índice de Desenvolvimento Rural (IDR) dos municípios do estado do Pará, utilizando-se a análise fatorial, com base nos trabalhos de Kageyama (2004), Souza (2014) e Santos (2016). No entanto, outros trabalhos sobre a dinâmica econômica da Amazônia e do Pará foram escritos, entre eles: Costa (2006) pesquisou sobre a importância da agropecuária e os fundamentos do desenvolvimento rural na Amazônia. Costa (2009 e 2010) delineou as trajetórias tecnológicas como objeto de políticas públicas, tendo como marco o mercado e as terras na Amazônia. Costa e Fernandes (2016) estudaram a dinâmica agrária, as instituições e a governança territorial para o desenvolvimento sustentável da Amazônia, lançando mão para análise as trajetórias tecnológicas nas economias rurais, e nas econômicas baseadas em sistemas agroflorestais. 


\section{Metodologia}

\subsection{A análise fatorial}

A análise fatorial se refere a uma variedade de técnicas da estatística multivariada cujo objetivo é representar um conjunto de variáveis em termos de um menor número de variáveis hipotéticas (STEGE e PARRÉ, 2011). As variáveis hipotéticas recebem o nome de fatores comuns e vão estar relacionadas com as variáveis originais através de um modelo linear (MINGOTI, 2005). De acordo com Melo e Parré (2007) esta técnica permite extrair um número reduzido de fatores, que são combinações lineares das variáveis originais, perdendo o mínimo de informações. A análise fatorial pode ser realizada através do método de componentes principais, que faz com que o primeiro fator contenha o maior percentual de explicação da variância total das variáveis da amostra; o segundo fator contenha o segundo maior percentual, e assim por diante (MELO e PARRÉ, 2007).

O método de análise fatorial pode ser expresso na forma matemática através de uma combinação linear entre as variáveis $\left(X_{i}\right)$ e $\mathrm{K}$ fatores comuns $(F)$ :

$X_{i}=A_{i 1} F_{1}+A_{i 2} F_{2}+\cdots+A_{i k} F_{k}+U_{i}+E_{i}$

Onde: $A_{i k}$ - Cargas fatoriais, usadas para combinar linearmente os fatores comuns.

$F_{1}, F_{2}, \ldots, F_{k}$ - Fatores comuns.

$U_{i}$ - Fator único

$E_{i}$ - Fator de erro

As cargas fatoriais indicam a intensidade das relações entre as variáveis normalizadas $X_{i}$ e os fatores. Quanto maior uma carga fatorial, mais associada com o fator se encontra a variável. A variância comum $h_{i}{ }^{2}$, ou comunalidade, representa quanto da variância total de $X_{i}$ é reproduzida pelos fatores comuns, sendo calculada a partir do somatório ao quadrado das cargas fatoriais. A variância única $U_{i}$ é a parte da variância total que não se associa com a variância das outras variáveis. $O$ termo $E_{i}$ representa o erro de observação, de mensuração ou de especificação do modelo.

A medida denominada de autovalor, ou raiz característica, expressa a variância total do modelo explicada por cada fator. De acordo com Mingoti (2005) o seu valor é o somatório dos quadrados das cargas fatoriais de cada variável associada ao fator específico e refletem a importância relativa de cada fator, bem como a variância de cada um deles. É através desse valor que se define quantos fatores serão retidos. A quantidade de fatores retidos será igual ao número de autovalores maiores ou igual a 1, a fim de manter no sistema novas dimensões que representem pelo menos a informação de variância de uma variável original. 0 autovalor divido pelo número de variáveis $\left(\mathrm{X}_{\mathrm{i}}\right)$ determina a proporção da variância total explicada pelo fator. Esse valor irá revelar o quanto cada fator consegue captar da variabilidade original das variáveis. Para facilitar a interpretação destes fatores é realizada uma rotação ortogonal pelo método varimax, que procura minimizar o número de variáveis fortemente relacionadas com cada fator, permitindo, assim, obter fatores mais facilmente interpretáveis (MINGOTI, 2005). 
Através da utilização do software Stata (versão MP 13), foram obtidos os fatores e selecionados os que apresentaram valores maiores que 1. Identificados os fatores, é feita a estimação do escore fatorial, por meio do método semelhante ao da regressão. O escore para cada observação (município) é resultado da multiplicação do valor (padronizado) das variáveis pelo coeficiente do escore fatorial correspondente, sendo a expressão geral para estimação do j-ésimo fator $F_{j}$ dada por:

$F_{j}=W_{j 1} X_{1}+W_{j 2} X_{2}+W_{j 3} X_{3}+\cdots+W_{j p} X_{p}$

em que os $W_{i j}$ são os coeficientes dos escores fatoriais e $p$ é o número de variáveis.

Os escores fatoriais de cada fator possuem distribuição normal, com média zero e variância unitária e, desse modo, podem ser utilizadas para indicar a posição relativa de cada observação relativamente ao conceito expresso pelo fator. Assim, a partir da matriz dos escores fatoriais, é possível construir um índice para hierarquizar as observações (MINGOTI, 2005).

A verificação do grau de desenvolvimento de cada município paraense foi feita através dos escores fatoriais, ou seja, dos valores dos fatores para cada uma das $143^{1}$ observações (municípios). Através da equação 3, obteve-se o Índice Bruto de Desenvolvimento, por meio do cálculo da média dos fatores (ponderada pela variância) pertencentes a cada observação. Como procedeu-se à análise fatorial pelo método de componentes principais (que faz com que o primeiro fator contenha o maior percentual de explicação da variância total das variáveis da amostra, o segundo fator contenha o segundo maior percentual, e assim por diante), a ponderação pela proporção de explicação da variância total exprime a importância relativa de cada fator (MINGOTI, 2005).

$I B=\frac{\sum_{i=1}^{5}\left(w_{i} F_{i}\right)}{\sum_{i=1}^{5} w_{i}}$

Sendo: IB = Índice bruto (média ponderada dos escores fatoriais)

$w_{i}=$ Proporção da variância explicada por cada fator

$F_{i}=$ Escores fatoriais

A partir daí, interpola-se os resultados, considerando-se o maior valor como 100 e o menor como zero, obtendo o Índice de Desenvolvimento Rural (IDR) para cada município. A classificação do Índice de Desenvolvimento Rural (IDR) para os municípios do estado do Pará, baseou-se nos trabalhos de Melo e Parré (2007) e Santos (2016). Dessa forma os municípios do Pará foram classificados de acordo com o grau de dinamicidade. A Tabela 1 resume a classificação definida.

Tabela 1 - Classificação do Índice de Desenvolvimento Rural (IDR)

\begin{tabular}{l|l}
\hline Muitíssimo Alto (MMA) & Muito Alto (MA) \\
\hline Alto (A) & Médio (M) \\
\hline Muito Baixo (MB) & Muitíssimo Baixo (MMB) \\
\hline
\end{tabular}

Fonte: Adaptado de Melo e Parré (2007) e Santos (2016).

\footnotetext{
${ }^{1}$ Não foi incluído o município de Mojuí dos Campos nesta análise, pois no período de pesquisas realizadas pelo IBGE, de 2000 a 2010, o mesmo ainda pertencia ao município de Santarém.
} 
Foram considerados como grau de desenvolvimento muitíssimo alto (MMA) aqueles que apresentaram resultados com três desvios-padrão acima da média; muito alto (MA) aqueles com resultados entre dois e três desvios-padrão acima da média; alto $(A)$, aqueles com valores entre um e dois desvios-padrão acima da média; médio $(M)$, os que apresentaram resultado entre a média e um desviopadrão acima da média; baixo (B), aqueles com resultados no intervalo entre a média e um desvio-padrão abaixo da média; muito baixo (MB), aqueles que tiveram resultados entre um e dois desvios-padrão abaixo da média; muitíssimo baixo $(M M B)$, os que tiveram resultados no intervalo entre dois e três desvios-padrão abaixo da média (MELO e PARRÉ, 2007). Para verificar a adequabilidade do modelo é utilizada a estatística de Kaiser-Meyer-Olkin (KMO) ${ }^{2}$ e o teste de esfericidade de Barlett ${ }^{3}$.

\subsection{Descrição das variáveis}

A análise do desenvolvimento rural como um todo vai além do domínio da economia, identificado pelo progresso econômico. Engloba um conjunto de indicadores que interagem entre si, reunindo aspectos sociais, demográficos, econômicos e ambientais, ou seja, trata-se de um fenômeno multidimensional. Utilizando estas quatro dimensões é possível encontrar variáveis que podem ser utilizadas para tentar explicar a causa ou desigualdade do desenvolvimento.

As variáveis utilizadas neste trabalho foram extraídas de Santos (2016). Segue Quadro 1 com cada uma das variáveis e suas fontes de dados.

Quadro 1. Variáveis selecionadas para o cálculo do IDR

\begin{tabular}{|c|c|c|c|c|}
\hline Dimensão & $\begin{array}{c}\text { Variável e sua relação com } \\
\text { o desenvolvimento: positiva } \\
\text { (+) ou negativa (-) }\end{array}$ & Forma de Cálculo & Unidade & Fonte de Dados \\
\hline \multirow{4}{*}{ 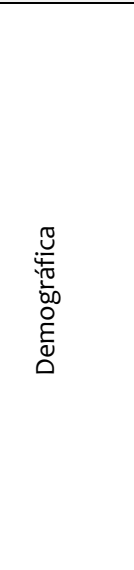 } & $\begin{array}{l}\text { X1) Densidade demográfica } \\
\text { (padronizada)* }(+)\end{array}$ & $\begin{array}{l}\text { Proporção de habitantes (total) do } \\
\text { município em relação a sua área }\end{array}$ & $\mathrm{hab} / \mathrm{km}^{2}$ & $\begin{array}{l}\text { Censo } \\
\text { Demográfico } \\
\text { IBGE (2010) }\end{array}$ \\
\hline & $\begin{array}{l}\text { X2) Variação da população } \\
\text { rural (padronizada)* }(+)\end{array}$ & $\begin{array}{l}\text { Taxa de crescimento da população } \\
\text { rural entre os anos de } 2010 \text { e } 2000\end{array}$ & $\%$ & $\begin{array}{l}\text { Censo } \\
\text { Demográfico } \\
\text { IBGE (2000 e } \\
2010)\end{array}$ \\
\hline & $\begin{array}{l}\text { X3) Proporção de população } \\
\text { rural do município }(+)\end{array}$ & $\begin{array}{l}\text { Proporção da população rural do } \\
\text { município pela sua população total }\end{array}$ & $\%$ & $\begin{array}{l}\text { Censo } \\
\text { Demográfico } \\
\text { IBGE (2010) }\end{array}$ \\
\hline & $\begin{array}{l}\text { X4) Proporção de população } \\
\text { de migrantes (+) }\end{array}$ & $\begin{array}{l}\text { Proporção da população que não } \\
\text { morou sempre no município pela sua } \\
\text { população total }\end{array}$ & $\%$ & $\begin{array}{l}\text { Censo } \\
\text { demográfico } \\
\text { IBGE (2010) }\end{array}$ \\
\hline \multirow[t]{2}{*}{ 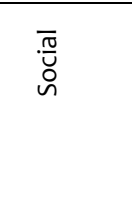 } & $\begin{array}{l}\text { X5) Índice } r \text { de } \\
\text { Desenvolvimento Humano } \\
(\text { IDH }) \text { - Longevidade }(+)\end{array}$ & Esperança de vida ao nascer & Escala (0-1) & $\begin{array}{l}\text { ADH - Atlas do } \\
\text { Desenvolviment } \\
\text { o Humano no } \\
\text { Brasil (2013) }\end{array}$ \\
\hline & x6) Taxa de alfabetização & População rural alfabetizada em & $\%$ & Censo \\
\hline
\end{tabular}

\footnotetext{
${ }^{2}$ Mais informações ver Mingoti (2005, p. 137).

${ }^{3}$ Mais informações ver Mingoti (2005, p. 138).
} 


\begin{tabular}{|c|c|c|c|c|}
\hline & $(+)$ & relação à população rural & & $\begin{array}{l}\text { Demográfico } \\
\text { IBGE (2010) }\end{array}$ \\
\hline & $\begin{array}{l}\text { X7) Intensidade } \quad \text { de } \\
\text { pobreza }{ }^{4 * *}(-)\end{array}$ & $\begin{array}{l}\text { Distância que separa a renda domiciliar } \\
\text { per capita média dos indivíduos } \\
\text { pobres do valor da linha de pobreza, } \\
\text { medida em termos de percentual do } \\
\text { valor dessa linha de pobreza }\end{array}$ & $\%$ & $\begin{array}{l}\text { ADH - Atlas de } \\
\text { Desenvolviment } \\
\text { o Humano no } \\
\text { Brasil (2013) }\end{array}$ \\
\hline & $\begin{array}{l}\text { X8) Domicílios rurais com } \\
\text { abastecimento de água } \\
\text { proveniente da rede geral } \\
(+)\end{array}$ & $\begin{array}{l}\text { Proporção dos domicílios rurais servido } \\
\text { de água proveniente de uma rede } \\
\text { geral de abastecimento pelo total de } \\
\text { domicílios rurais }\end{array}$ & $\%$ & $\begin{array}{l}\text { Censo } \\
\text { Demográfico } \\
\text { IBGE (2010) }\end{array}$ \\
\hline & $\begin{array}{l}\text { X9) Domicílios rurais com } \\
\text { instalação de energia } \\
\text { elétrica de companhia } \\
\text { distribuidora (+) }\end{array}$ & $\begin{array}{l}\text { Proporção dos domicílios rurais que } \\
\text { possuem energia elétrica pelo total de } \\
\text { domicílios rurais }\end{array}$ & $\%$ & $\begin{array}{l}\text { Censo } \\
\text { Demográfico } \\
\text { IBGE (2010) }\end{array}$ \\
\hline & $\begin{array}{l}\text { X10) Domicílios rurais com } \\
\text { esgoto sanitário - fossa } \\
\text { séptica }(+)\end{array}$ & $\begin{array}{l}\text { Proporção de domicílios rurais com } \\
\text { esgoto sanitário - fossa séptica pelo } \\
\text { total de domicílios rurais }\end{array}$ & $\%$ & $\begin{array}{l}\text { Censo } \\
\text { Demográfico } \\
\text { IBGE (2010) }\end{array}$ \\
\hline \multirow{3}{*}{ 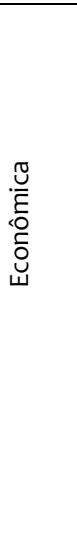 } & $\begin{array}{lr}\text { X11) Índice } & \text { de } \\
\text { Desenvolvimento } & \text { Humano } \\
(\text { IDH })-\text { Renda (+) } & \end{array}$ & $\begin{array}{l}\text { Soma da renda de todos os residentes } \\
\text { dividido pelo número de pessoas que } \\
\text { moram no município }\end{array}$ & Escala (0-1) & $\begin{array}{l}\text { ADH - Atlas do } \\
\text { Desenvolviment } \\
\text { o Humano no } \\
\text { Brasil (2013) }\end{array}$ \\
\hline & $\begin{array}{l}\text { X12) Valor bruto } \\
\text { produção } \\
\text { estabelecimento } \\
\text { agropecuário } \\
\text { (padronizado)* }(+)\end{array}$ & $\begin{array}{l}\text { Valor bruto da produção agropecuária } \\
\text { pelo número de estabelecimentos } \\
\text { agropecuários }\end{array}$ & $\mathrm{R} \$$ & $\begin{array}{l}\text { Censo } \\
\text { Agropecuário } \\
(2006)\end{array}$ \\
\hline & $\begin{array}{l}\text { X13) Valor bruto de } \\
\text { produção por pessoa } \\
\text { ocupada na agropecuária } \\
\text { (padronizado)* (+) }\end{array}$ & $\begin{array}{l}\text { Valor bruto da produção agropecuária } \\
\text { pelo número de pessoas ocupadas nos } \\
\text { estabelecimentos agropecuários }\end{array}$ & $\mathrm{R} \$$ & $\begin{array}{l}\text { Censo } \\
\text { Agropecuário } \\
(2006)\end{array}$ \\
\hline \multirow{3}{*}{ 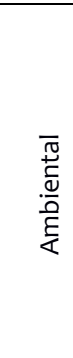 } & $\begin{array}{l}\text { X14) Estabelecimentos com } \\
\text { práticas de conservação }{ }^{5}(+)\end{array}$ & $\begin{array}{l}\text { Proporção de estabelecimentos rurais } \\
\text { que fazem uso de agrotóxicos pelo } \\
\text { total }\end{array}$ & $\%$ & $\begin{array}{l}\text { Censo } \\
\text { Agropecuário } \\
(2006)\end{array}$ \\
\hline & $\begin{array}{l}\text { X15) Matas naturais e } \\
\text { plantadas }{ }^{6}\end{array}$ & $\begin{array}{l}\text { Proporção de matas naturais e } \\
\text { plantadas pela área total }\end{array}$ & $\%$ & $\begin{array}{l}\text { Censo } \\
\text { Agropecuário } \\
(2006)\end{array}$ \\
\hline & $\begin{array}{l}\text { X16) Estabelecimentos que } \\
\text { utilizam agrotóxico }{ }^{7 * *}(-)\end{array}$ & $\begin{array}{l}\text { Proporção de estabelecimentos rurais } \\
\text { que fazem uso de agrotóxicos pelo }\end{array}$ & $\%$ & $\begin{array}{l}\text { Censo } \\
\text { Agropecuário }\end{array}$ \\
\hline
\end{tabular}

${ }^{4}$ O Atlas de Desenvolvimento Humano considerou para o ano de 2010 a linha de pobreza no valor de R\$ 140,00 de renda familiar per capita de pobres. O cálculo da Intensidade de Pobreza também considerou este mesmo valor de linha de pobreza $(\mathrm{R} \$ 140,00)$. Portanto, a Intensidade de Pobreza é a diferença da renda domiciliar per capita média dos indivíduos pobres (renda domiciliar per capita inferior à $R \$ 140,00$ ) do valor de $R \$ 140,00$, dividido por $\mathrm{R} \$ 140,00$ e multiplicado por 100.

5 Para determinar os estabelecimentos com práticas de conservação somaram-se os estabelecimentos que não praticam atos de conservação do solo com os que praticam queimadas, e subtraiu do total de estabelecimentos.

${ }^{6}$ Para a variável matas naturais e plantadas foram consideradas as áreas de matas e/ou florestas naturais destinadas à preservação permanente ou reserva legal; as áreas de matas e/ou florestas naturais (exclusive área de preservação permanente e as áreas em sistemas agroflorestais) e a área cultivada com espécies florestais também foram usadas para lavouras e pastejo de animais. 


\begin{tabular}{|c|c|c|c|}
\hline & total & $\%$ & (2006) \\
\hline $\begin{array}{l}\text { X17) Estabelecimentos com } \\
\text { uso de adubação orgânica } \\
(+)\end{array}$ & $\begin{array}{l}\text { Proporção de estabelecimentos rurais } \\
\text { que fazem uso de adubação orgânica } \\
\text { pelo total }\end{array}$ & $\%$ & $\begin{array}{l}\text { Censo } \\
\text { Agropecuário } \\
(2006)\end{array}$ \\
\hline $\begin{array}{l}\text { X18) Proporção de } \\
\text { domicílios rurais com coleta } \\
\text { de lixo - coletado por } \\
\text { serviço de limpeza e } \\
\text { caçamba de serviço de } \\
\text { limpeza (+) }\end{array}$ & $\begin{array}{l}\text { Proporção dos domicílios rurais que } \\
\text { possuem lixo coletado pelo total de } \\
\text { domicílios rurais }\end{array}$ & $\%$ & $\begin{array}{l}\text { Censo } \\
\text { Demográfico } \\
\text { IBGE (2010) }\end{array}$ \\
\hline
\end{tabular}

Fonte: Elaboração própria a partir dos dados do IBGE (2010), PNUD (2013; Censo Agropecuário (2006).

* Segundo Kageyama (2004) a padronização consiste em uma transformação algébrica para que o índice varie no intervalo de zero a um. Essa transformação é feita da seguinte forma: (valor da variável - mínimo) / (máximo - mínimo).

** Quando uma variável é negativa (-) em relação ao desenvolvimento, ela é invertida, ou seja, é subtraída uma unidade do resultado.

Os indicadores demográficos ( $\mathrm{X}_{1}$ a $\left.\mathrm{X}_{4}\right)$ procuram medir o dinamismo populacional que deveria favorecer o desenvolvimento rural. Segundo Kageyama (2004 e 2008) uma densidade demográfica elevada indica menor isolamento das áreas rurais, o que significa maior diversificação, multifuncionalidade e progresso social; uma grande população rural e seu crescimento na década indica maior capacidade da área rural de reter população; a migração de pessoas de outros municípios reforça a capacidade de atração daquele município na região.

As variáveis $X_{5}$ a X10 são indicadores sociais de bem-estar dos residentes nas áreas rurais e demonstram se as pessoas ali residentes desfrutam de melhor qualidade de vida ou não. A variável Índice de Desenvolvimento Humano (IDH) Longevidade representa a esperança de vida ao nascer para o município como um todo, refletindo assim as condições de saúde e de salubridade no local. Quanto a taxa de alfabetização rural, é um indicador educacional que tem correspondência positiva com o IDR.

A intensidade de pobreza é um indicador que permite obter informações pelo desvio médio entre a renda dos pobres e o valor da linha de pobreza e que mede a distribuição média da renda dos pobres no que se refere à linha de pobreza, ou seja, auxilia a identificar os mais pobres dos pobres (MELO, 2005). A variável tem uma correspondência negativa com o IDR e, portanto, utilizou-se um índice de intensidade de não-pobreza. As variáveis relacionadas às condições de infraestrutura dos domicílios rurais (instalação sanitária, água encanada e energia elétrica) estão ligadas a qualidade de vida e afetam positivamente o IDR (STEGE e PARRÉ, 2011). As variáveis $X 11$ a X13 são indicadores de desempenho econômico relacionados ao valor do setor agropecuário no município. A variável índice de Desenvolvimento Humano (IDH) - Renda revela melhoria no sistema e tem relação positiva com o desenvolvimento rural (CONTERATO et al., 2009). As variáveis relacionadas a produtividade dos fatores de produção afetam de forma positiva o

\footnotetext{
${ }^{7}$ Foram considerados como estabelecimentos que utilizam agrotóxico a soma dos que utilizam, mais os que utilizam, mas não precisaram utilizar em 2006.

${ }^{8}$ Estabelecimentos com uso de adubação orgânica é o resultado da soma de esterco e/ou urina animal + adubação verde + vinhaça + húmus de minhoca + biofertilizantes + inoculantes + composto orgânico.
} 
desenvolvimento rural (STEGE e PARRÉ, 2011). A produtividade do trabalho na agricultura é medida pelo quociente entre o Valor Bruto da Produção Agropecuária (VBP) e o pessoal ocupado na agropecuária (população ocupada na agricultura, pecuária, silvicultura, exploração florestal e pesca).

As variáveis X14 a X18 destacam a influência das questões ambientais na conservação do meio rural e seu desenvolvimento. Segundo Kageyama (2004), os indicadores de meio ambiente procuram contrapor a presença dos efeitos nocivos do modelo de modernização agrícola com os efeitos compensadores de práticas de conservação do solo. O uso de agrotóxicos possui uma relação negativa com o IDR e este indicador é transformado em não uso de agrotóxicos. A existência de matas naturais ou plantadas é um atributo importante para que, através da conservação da natureza, as áreas rurais cumpram a função de provedora de serviços ambientais e de bens públicos.

\section{Resultados e Discussão}

A tabela 2 apresenta uma estatística descritiva das variáveis utilizadas para construção do IDR para o estado do Pará.

Tabela 2 - Estatísticas descritivas das variáveis utilizadas

\begin{tabular}{lccc}
\hline Variáveis & Média & Mínino & Máximo \\
\hline X1 & 58,52 & 0,26 & 2477,59 \\
X2 & 0,16 & $-0,88$ & 1,09 \\
X3 & 0,48 & 0,00 & 0,88 \\
X4 & 0,37 & 0,06 & 0,85 \\
X5 & 0,77 & 0,72 & 0,83 \\
X6 & 0,79 & 0,57 & 0,95 \\
X7 & 52,41 & 35,20 & 74,40 \\
X8 & 0,25 & 0,00 & 0,85 \\
X9 & 0,63 & 0,01 & 0,98 \\
X10 & 0,08 & 0,00 & 0,40 \\
X11 & 0,57 & 0,45 & 0,75 \\
X12 & 35,61 & 3,89 & 788,49 \\
X13 & 7,43 & 0,74 & 66,17 \\
X14 & 0,20 & 0,00 & 0,97 \\
X15 & 0,40 & 0,01 & 0,86 \\
X16 & 0,11 & 0,00 & 0,45 \\
X17 & 0,08 & 0,00 & 0,58 \\
X18 & 0,17 & 0,00 & 0,77 \\
\hline
\end{tabular}

Fonte: Resultados da pesquisa.

A análise aplicada ao modelo possibilitou a extração de seis fatores com raiz característica maior que a unidade e que sintetizam as contidas nas 18 variáveis originais. Após a rotação, os seis fatores selecionados explicam, em conjunto, $68,77 \%$ da variância total das variáveis selecionadas, conforme Tabela 3. O uso da 
variância de 68,77\% é justificado por Hair et al. (2009), pois, segundo o autor, obter uma variância acumulada de $60 \%$ é satisfatório nas ciências sociais.

Tabela 3 - Raiz característica, percentual explicado por cada fator e variância acumulada

\begin{tabular}{c|c|c|c}
\hline Fator & Raiz característica & $\begin{array}{c}\text { Variância explicada } \\
\text { pelo fator (\%) }\end{array}$ & $\begin{array}{c}\text { Variância } \\
\text { acumulada (\%) }\end{array}$ \\
\hline F1 & 3,10379 & 17,24 & 17,24 \\
F2 & 3,03841 & 16,88 & 34,12 \\
F3 & 2,08767 & 11,60 & 45,72 \\
F4 & 1,63675 & 9,09 & 54,81 \\
F5 & 1,33650 & 7,43 & 62,24 \\
F6 & 1,17482 & 6,53 & 68,77
\end{tabular}

Fonte: Resultados da pesquisa.

O teste de Bartlett mostrou-se significativo, rejeitando a hipótese nula de que a matriz de correlação é uma matriz identidade. O teste de $\mathrm{KMO}$, para análise da adequabilidade da amostra apresentou valor de 0,6981 , indicando que a amostra é passível de ser analisada pelas técnicas de análise fatorial.

A Tabela 4 apresenta as cargas fatoriais e as comunalidades para os fatores considerados. Para sua interpretação foram consideradas apenas as cargas fatoriais com valores superiores a 0,50 (em negrito), buscando evidenciar os indicadores mais fortemente associados a determinado fator. Os valores encontrados para as comunalidades revelam que praticamente todas as variáveis têm sua variabilidade captada e representada pelos seis fatores.

Tabela 4 - Cargas fatoriais e comunalidades

\begin{tabular}{|c|c|c|c|c|c|c|c|}
\hline \multirow[t]{2}{*}{ Indicadores } & \multicolumn{6}{|c|}{ Cargas Fatoriais } & \multirow[t]{2}{*}{ Comunalidades } \\
\hline & $\mathrm{F} 1$ & $\mathrm{~F}_{2}$ & $F_{3}$ & $\mathrm{~F}_{4}$ & F5 & F6 & \\
\hline $\mathrm{X} 1$ & $-0,0358$ & 0,6194 & $-0,1681$ & 0,3461 & 0,3584 & $-0,0334$ & 0,6626 \\
\hline$X_{2}$ & 0,1968 & $-0,1141$ & 0,4174 & 0,5798 & $-0,1309$ & $-0,0279$ & 0,5801 \\
\hline$x_{3}$ & $-0,0903$ & $-0,7978$ & $-0,0711$ & 0,1988 & $-0,1435$ & $-0,0023$ & 0,7098 \\
\hline$X_{4}$ & 0,0476 & 0,4602 & 0,1659 & $-0,5625$ & $-0,0391$ & 0,2136 & 0,6052 \\
\hline$X_{5}$ & 0,0384 & 0,6906 & $-0,0136$ & 0,0149 & $-0,3818$ & $-0,1139$ & 0,6375 \\
\hline$x 6$ & 0,6589 & 0,2774 & $-0,0459$ & 0,1708 & $-0,0551$ & 0,0594 & 0,5489 \\
\hline$x_{7}$ & 0,3747 & 0,6397 & 0,1686 & $-0,0821$ & 0,2755 & $-0,1983$ & 0,6999 \\
\hline $\mathrm{X} 8$ & 0,7954 & $-0,1858$ & $-0,0003$ & 0,0907 & 0,1814 & $\begin{array}{c}- \\
0,0894\end{array}$ & 0,7162 \\
\hline X9 & 0,7208 & 0,1674 & 0,0352 & $-0,2660$ & 0,2921 & $-0,0112$ & 0,7049 \\
\hline
\end{tabular}




\begin{tabular}{llllllll} 
X10 & $\mathbf{0 , 6 5 6 3}$ & 0,0417 & $-0,1034$ & $-0,1167$ & $-0,0939$ & 0,0870 & 0,4732 \\
X11 & 0,2147 & $\mathbf{0 , 8 2 3 8}$ & 0,2220 & $-0,2605$ & $-0,0220$ & 0,1228 & 0,8574 \\
X12 & $-0,0189$ & 0,0838 & $\mathbf{0 , 9 2 8 8}$ & $-0,0149$ & 0,0513 & 0,0431 & 0,8748 \\
X13 & $-0,0408$ & 0,1338 & $\mathbf{0 , 9 1 4 8}$ & $-0,0994$ & 0,0948 & $-0,0563$ & 0,8785 \\
X14 & 0,1145 & 0,0558 & 0,1191 & $-0,1776$ & $\mathbf{0 , 7 9 1 3}$ & 0,0669 & 0,6925 \\
X15 & $-0,0909$ & $-0,0501$ & $-0,1538$ & $\mathbf{0 , 7 1 4 7}$ & $-0,1170$ & 0,2444 & 0,6186 \\
X16 & $-0,0501$ & $-0,0260$ & $-0,0082$ & 0,1024 & 0,0645 & $\mathbf{0 , 9 1 8 9}$ & 0,8622 \\
X17 & $\mathbf{0 , 5 2 9 7}$ & 0,1323 & $-0,0106$ & 0,2554 & 0,4012 & $-0,3314$ & 0,6342 \\
X18 & $\mathbf{0 , 7 3 6 2}$ & 0,1969 & 0,1518 & $-0,0095$ & $-0,0110$ & $-0,1314$ & 0,6213 \\
\hline
\end{tabular}

Fonte: Resultados da pesquisa

Percebe-se que o fator $\mathrm{F} 1$ está positiva e fortemente relacionado com o indicador X6, que expressa a taxa de alfabetização rural; com as variáveis X8, X9 e X10, proporção de domicílios rurais com abastecimento de água, com energia elétrica e com esgoto sanitário/fossa séptica, respectivamente, ou seja, variáveis ligadas a infraestrutura no meio rural; com a variável X17, estabelecimento com 0 uso de adubação orgânica; e X18, que refere-se a domicílios rurais com coleta de lixo, ligado ao serviço fornecido ao meio rural; ambos relacionados a qualidade ambiental. O fator 1 explica 17,24\% do total da variância acumulada e está ligado às instalações e serviços fornecidos as populações e aos domicílios rurais, o que Kageyama (2008) trata como condições de bem-estar nos domicílios rurais.

$O$ fator F2 é positivamente relacionado com as variáveis $X_{1}$, de densidade demográfica; X5, X11 e X7, ou seja, IDH - Longevidade, IDH - Renda e intensidade de não pobres, respectivamente. Entretanto, o fator F2 é negativamente relacionado a variável $X_{3}$, a proporção de população rural no município. O fator dá ênfase a indicadores de ordem social para o município como um todo, que podem revelar municípios com maior qualidade de vida. Além disso, pode demonstrar que municípios com maior crescimento urbano, de maior densidade demográfica, proporcionam maior desenvolvimento rural e, por outro lado, municípios com maior população rural comparada a urbana, estão negativamente associados aos indicadores sociais. Este fator responde por $16,88 \%$ da variância acumulada e corresponde a condicionantes demográficas que podem explicar a relação intrínseca entre crescimento urbano e indicadores sociais de desenvolvimento.

O fator $\mathrm{F} 3$ possui uma relação forte com as variáveis X12 e X13, ou seja, $\mathrm{O}$ valor bruto da produção por estabelecimento agropecuário e por pessoa ocupada na agropecuária, respectivamente. É um fator ligado aos indicadores de desempenho econômico derivados da produção e produtividade agropecuária, característicos do modelo de produção agropecuário moderno.

O fator F4 está relacionado com as variáveis X2 e X15 que correspondem ao crescimento da população rural no período medido e a cobertura de matas naturais ou plantadas, respectivamente. Por outro lado, há uma relação negativa com a variável X4, a população de migrantes. Ou seja, este fator revela uma forte relação do crescimento populacional rural naqueles municípios de maior riqueza de 
recursos naturais, o que revela o fenômeno de expansão de fronteira agrícola, em curso, em algumas regiões do estado. Entretanto, há uma maior expansão da população rural não derivada necessariamente da migração, mas de deslocamento de população urbana para a área rural.

O fator $\mathrm{F}_{5}$ possui uma relação com a variável X14, que abrange os estabelecimentos com práticas de conservação. É um fator que leva em consideração exclusivamente o aspecto ambiental do modelo de produção, por sua vez o fator $\mathrm{F} 6$, também, possui uma relação com outro indicador ambiental relativo ao modelo de produção, a variável $\mathrm{X} 16$, indicador ambiental que revela estabelecimentos que não utilizam agrotóxico.

Uma vez verificadas as cargas fatoriais, o passo seguinte é observar os escores fatoriais, ou seja, o valor do fator para cada município do estado. A análise do fator deve ser feita levando em conta que seus escores originais, quando considerados todos os municípios em conjunto, são variáveis com média e desvio padrão igual a 1. Portanto, pode-se interpretar que os escores com valores próximos de zero indicam nível de desenvolvimento médio e, quanto maior em relação a zero for o fator, mais avançado será o município, no que se refere ao significado do fator em consideração. A tabela 3 apresenta os resultados por município. O IDR médio situou-se em 41,64. A partir daí, foram definidas as categorias de desenvolvimento rural.

A Tabela 5 mostra que, de acordo com a classificação, as regiões Metropolitana e Rio Capim possuem quatro municípios com grau de IDR muitíssimo alto e muito alto (MMA e MA). Na categoria de alto desenvolvimento (A) não se registra a presença de nenhum município das regiões Lago de Tucuruí, Marajó, Tapajós e Xingu. Tanto na categoria de médio desenvolvimento $(M)$ quanto na de baixo desenvolvimento (B) são registrados municípios de todas as regiões, com exceção da Metropolitana. Na categoria de desenvolvimento muito baixo (MB) há municípios das regiões do Araguaia, Baixo Amazonas, Carajás, Marajó, Rio Capim, Tapajós e Xingu. A região Marajó tem três municípios na mais baixa categoria de desenvolvimento (MMB).

Tabela 5 - Grau do Índice de Desenvolvimento Rural (IDR) dos municípios paraenses

\begin{tabular}{lccccccc}
\hline Região & \multicolumn{7}{c}{ Número do Municípios por grau de desenvolvimento } \\
& MMA & MA & A & M & B & MB & MMB \\
\hline Araguaia & 0 & 0 & 2 & 5 & 7 & 1 & 0 \\
\hline Baixo Amazonas & 0 & 0 & 1 & 5 & 5 & 1 & 0 \\
\hline Carajás & 0 & 0 & 1 & 2 & 7 & 2 & 0 \\
\hline Guamá & 0 & 0 & 6 & 9 & 3 & 0 & 0 \\
\hline Lago de Tucuruí & 0 & 0 & 0 & 1 & 6 & 0 & 0 \\
\hline Marajó & 0 & 0 & 0 & 2 & 5 & 6 & 3 \\
\hline Metropolitana & 2 & 1 & 2 & 0 & 0 & 0 & 0 \\
\hline Rio Caeté & 0 & 0 & 1 & 6 & 8 & 0 & 0 \\
\hline
\end{tabular}




\begin{tabular}{lccccccc}
\hline Rio Capim & 1 & 0 & 1 & 5 & 8 & 1 & 0 \\
\hline Tapajós & 0 & 0 & 0 & 2 & 3 & 1 & 0 \\
\hline Tocantins & 0 & 0 & 2 & 3 & 6 & 0 & 0 \\
\hline Xingu & 0 & 0 & 0 & 4 & 5 & 1 & 0
\end{tabular}

Fonte: Resultados da pesquisa.

Legenda: Muitíssimo Alto (MMA); Muito Alto (MA); Alto (A); M (Médio); Muito Baixo (MB); Muitíssimo Baixo (MMB).

Somando-se os municípios abaixo da linha de médio desenvolvimento chegase ao total de 79 ou $55,24 \%$ dos municípios, ou seja, mais da metade dos municípios do estado do Pará encontra-se com baixo grau de desenvolvimento rural. A região Metropolitana é a única que apresenta todos os municípios classificados entre graus de desenvolvimento alto e muitíssimo alto. A região ainda concentrava $45 \%$ do PIB estadual no ano de 2005 (SILVA, 2012). A elevada concentração de população urbana proporciona maior mercado consumidor para os produtos provenientes das áreas rurais, estimulando a diversificação da produção. Belém, Ananindeua e Marituba apresentam melhores indicadores sociais. Benevides, Marituba e Santa Bárbara do Pará apresentam maior acesso a infraestrutura e serviços no meio rural. Há um aumento da população rural em municípios de grande porte como Belém e Ananindeua. Conforme explica Silva (1997), nas regiões metropolitanas as populações são atraídas por empregos gerados por indústrias e agroindústrias instaladas nas áreas rurais, a expansão de condomínios rurais e zonas suburbanas e atividades ligadas a preservação ambiental.

O Guamá é a segunda região em proporção de municípios com maior desenvolvimento rural. A região beneficia-se da proximidade com a área metropolitana e o acesso ao seu mercado consumidor. O principal município da região é Castanhal que, segundo o Atlas de Integração Regional do Estado do Pará (PARÁ, 2010), possui uma importante produção industrial e funciona como um centro comercial fornecer de insumos e equipamentos para a agricultura. A população rural é beneficiada pelo acesso a infraestrutura e serviços em todos os municípios. Os indicadores sociais, todavia, ainda são desiguais entre os municípios. O município de São João da Ponta destaca-se pela alta produção por estabelecimento e por pessoa ocupada na agropecuária, sendo o seu principal produto a mandioca.

Os municípios da região Rio Caeté estão em sua maioria classificados com IDR abaixo da média do estado. A maior parte dos municípios desta região, conhecida anteriormente como Bragantina, teve grande participação na riqueza estadual nos séculos passados, porém se distanciou da rota dos investimentos dos interesses do capital privado e dos interesses governamentais, em especial, porque tinha uma produção mais restrita à capital Belém (COSTA, 2006 e 2009; SILVA, 2012).

Em geral, a maioria dos municípios do Rio Caeté apresentou melhorias nos indicadores de acesso a infraestrutura e serviços pelos domicílios rurais. Entretanto, os indicadores sociais da grande maioria são baixos. Destacam-se os municípios de Salinópolis, que possui o turismo como importante atividade econômica, e 
Capanema com bons indicadores sociais. Bragança é o município mais populoso da região (PARÁ, 2010).

A região Rio Capim, chamada anteriormente de Guajarina, começou a ser colonizada entre a década de 1940 e 1950, com orientação ao abastecimento do mercado de Belém (SILVA, 2012). Apresenta maior variabilidade na classificação dos municípios quanto ao IDR. A maioria dos municípios está entre médio e baixo IDR. Em geral, apresentam indicadores razoáveis de acesso a infraestrutura e serviços pela população rural, mas baixos indicadores sociais para o município. O município de Nova Esperança do Piriá é o de mais baixo desenvolvimento na região. Entretanto há um município com grau de desenvolvimento muito alto, Ulianópolis, e outro com grau de desenvolvimento alto, Paragominas.

Pode-se, então, construir uma figura que melhor visualiza como está a distribuição do desenvolvimento rural dentro do estado, apresentado na Figura 1.

Figura 1 - Espacialidade do Índice de Desenvolvimento Rural dos municípios do Pará
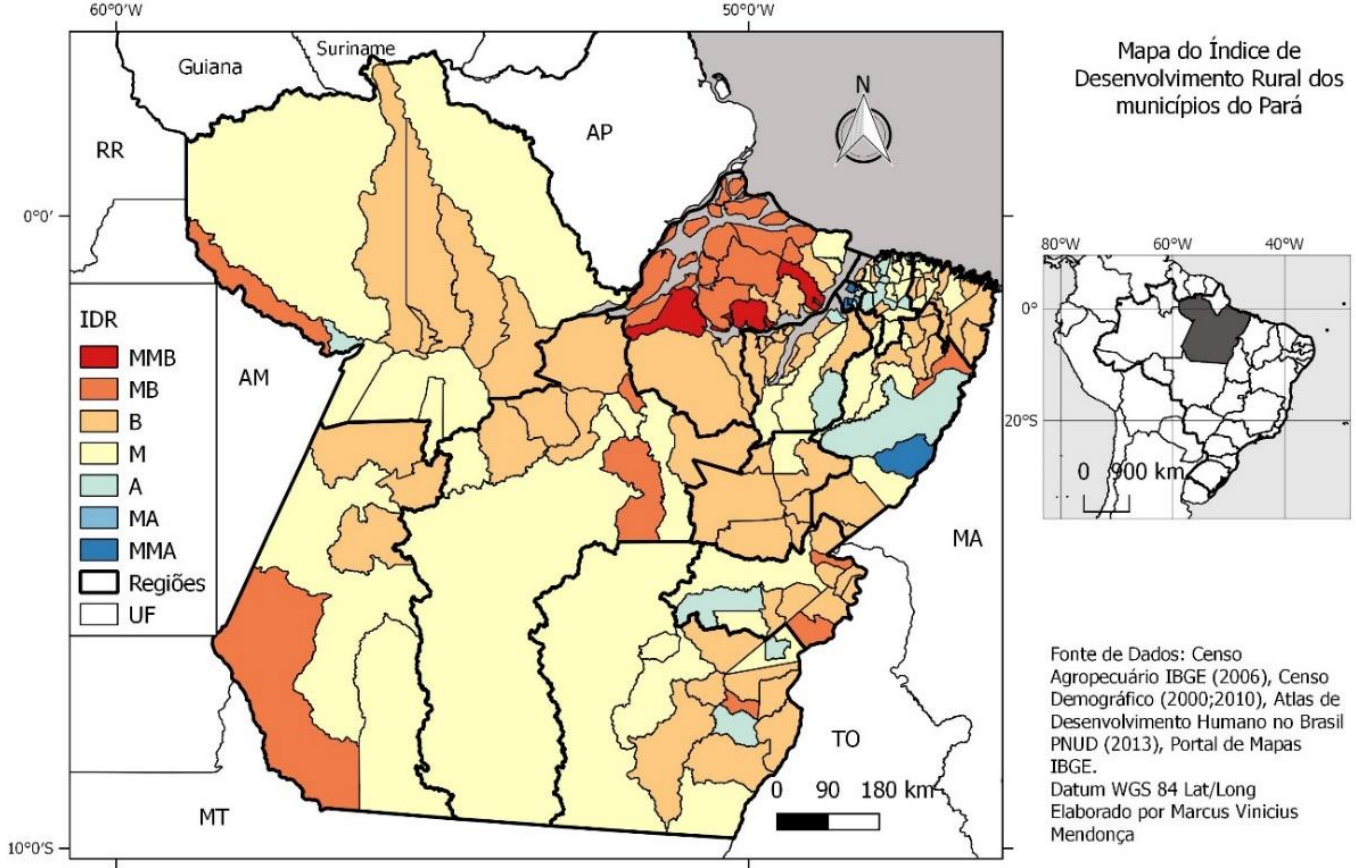

Fonte: Elaboração própria, a partir dos dados obtidos do IBGE (2018).

Ulianópolis e Paragominas destacam-se com índices econômicos de produção por estabelecimento e por pessoa ocupada na agropecuária. Em Ulianópolis desenvolve-se uma agricultura altamente tecnificada através do plantio de cana para produção de açúcar. Este município, porém, apresenta infraestrutura e indicadores sociais piores que vários municípios da região. O município de Paragominas apresenta maior destaque na região, constituindo-se como um provedor de serviços, máquinas e equipamentos. No setor agropecuário também se destaca através da produção de grãos e pecuária.

$\mathrm{Na}$ região Tocantins ocorre uma característica que diferencia estes municípios entre si que é o meio de transporte. Parte deles são atravessados pelo rio Tocantins e os principais acessos são pelos rios. Em outros os acessos principais são por estradas (OLIVEIRA e PIFFER, 2018). Municípios como Barcarena e Tailândia 
apresentam um alto IDR, com bons resultados para infraestrutura e serviços na área rural e indicadores sociais. Em Barcarena está presente o projeto Albrás-Alunorte onde ficam as maiores fábricas de alumínio do país, constituindo-se em um polo na região. Moju e Tailândia apresentaram alta produtividade rural, sendo municípios produtores de óleo de dendê. Porém, os indicadores sociais de Moju são baixos. Os municípios atravessados por rios mantêm uma boa cobertura florestal e apresentam aumento da população rural. Por outro lado, os indicadores sociais e de infraestrutura e serviços para o meio rural para esses municípios são baixos.

Os municípios da região Marajó são aqueles que apresentam os piores indicadores de desenvolvimento rural. Sete municípios da região figuram entre os dez piores IDR do estado. A região apresenta baixa densidade demográfica, com elevada proporção de população rural, o que traduz pouco desenvolvimento urbano e indicadores sociais baixos. Os indicadores de bem estar dos domicílios rurais são os piores do estado, devido à pouca infraestrutura e serviços fornecidos a população rural. Soure e Salvaterra apresentaram IDR dentro da média estadual, com melhores indicadores de infraestrutura para o meio rural. Breves é o município mais populoso da região (PARÁ, 2010). A ausência de dados para alguns indicadores ambientais de alguns desses municípios pode ter rebaixado um pouco o índice final do IDR, sem, entretanto, alterar substancialmente a tabela de classificação. Melgaço é o município com o pior IDR do estado, o que tem correspondência com a classificação de pior IDH do país em 2010 (PNUD, 2013), com destaque para as altas taxas de analfabetismo.

Na região Baixo Amazonas destaca-se o município de Terra Santa com alto IDR, com bons indicadores de bem estar para os domicílios rurais. Santarém possui os melhores indicadores sociais e é o município mais populoso da região e provedor de serviços administrativos, educacionais e de outras ordens na região (RODRIGUES, 2016). Os municípios de Oriximiná e Alenquer, onde se encontra instalado o projeto de mineração de bauxita Rio do Norte, apresentaram médio e baixo IDR. Ou seja, a implantação de grandes projetos minerais na região não trouxe impactos muito positivos nas áreas rurais. Faro possui o mais baixo IDR na região.

Os municípios da região Tapajós apresentam baixo IDR em geral. A densidade demográfica é baixa, com elevada proporção de população rural. Os melhores indicadores sociais encontram-se em Novo Progresso e Itaituba que apresentam IDR médio. Itaituba é o município mais populoso da região (PARÁ, 2010). Entretanto, os indicadores de bem estar para os domicílios rurais são baixos. Jacareacanga é o município com mais baixo IDR na região, com indicadores de cobertura de infraestrutura e serviços rurais muito baixos.

Na região Xingu, Altamira é o município polo. A região apresenta bons indicadores sociais, entretanto, com indicadores baixos de bem-estar para os domicílios rurais, assim como todos os demais municípios da região. Assim como a região Tapajós, esta é uma região de ocupação mais recente, a partir da implantação da rodovia Transamazônica na década de 1970, e com precária infraestrutura rural (OLIVEIRA; PIFFER, 2016). O município de Senador José Porfírio apresentou o IDR mais baixo da região.

Os municípios da região do Lago do Tucuruí em geral apresentaram baixo IDR. Apenas Breu Branco apresentou IDR médio. Tucuruí, onde está implantada a 
hidrelétrica de Tucuruí, apresenta os melhores indicadores sociais. Entretanto, praticamente todos os municípios da região apresentam indicadores de infraestrutura e serviços para a área rural baixos.

Na região Carajás ocorre um município com alto IDR, Parauapebas, onde está instalado o projeto de extração de minério de ferro de Carajás desde a década de 1980. Marabá, município que centraliza equipamentos e serviços na região, apresenta somente um médio IDR. Canaã dos Carajás, onde está instalado outro grande projeto de mineração também apresenta médio IDR. Os demais municípios apresentam baixos indicadores sociais e de infraestrutura para o desenvolvimento rural. Nota-se uma redução generalizada da população rural nos municípios desta região durante o período estudado. Uma das hipóteses é que estes municípios tenham perdido população rural para áreas urbanas dos municípios mineradores dentro da própria região, tendo em vista a grande expansão populacional nestes últimos.

Pode ser verificada uma correlação entre a redução da população rural e a reduzida proporção de áreas de mata nativa nesta região (F4). Isto pode ser explicado devido a atividade pecuária bovina ser a principal forma de exploração agropecuária na região. A expansão da pecuária ocorre com o avanço em áreas de floresta e, em pequenas áreas, isso leva ao que é chamado de "crise da capoeira", devido ao aumento desproporcional das pastagens e a uma "crise técnica" da pecuária devido à sobrelotação (HURTIENNE, 2005). As áreas antigas tornam-se improdutivas e com a redução das áreas florestais, o agricultor não encontra novas reservas para dar continuidade a sua produção e a "estratégia de fronteira" descrita por Hurtienne (2005) e Costa (2009), pode estar sendo prejudicada.

Na região Araguaia, o município de Sapucaia apresentou alto IDR, devido aos componentes econômicos de produtividade por estabelecimento e por pessoa ocupada na agropecuária. No município há grandes fazendas de criação de rebanho bovino com maior uso de tecnologia. Com bons indicadores sociais, Redenção também apresenta alto IDR, destacando-se como um provedor de serviços para o setor agropecuário na região, apesar de não se destacar tanto pela concentração populacional. Em geral, os municípios da região apresentam bons indicadores sociais, porém com baixos indicadores de bem-estar para os domicílios rurais. O pior IDR foi registrado para o município de Pau D’Arco. Boa parte destes municípios apresentou o mesmo fenômeno de redução da população rural que a região de Carajás. Segundo Silva (2012) a pecuária é um componente muito importante no crescimento do PIB nesta região.

\section{Considerações Finais}

O desenvolvimento rural é um fator relacionado a múltiplos aspectos da vida no campo. O estado do Pará destaca-se na região Amazônica pela presença de populações rurais. Os grandes projetos na Amazônia e as políticas de colonização da região levaram a ocupação de praticamente todo território paraense. Este fluxo em tão pouco espaço de tempo foi feito de forma desordenada, tendo impactos sociais e ambientais. Procurando dimensionar as diferenças nas áreas rurais, classificou-se os municípios do estado em diferentes graus de desenvolvimento, a partir da análise fatorial. 
A região Metropolitana aparece ainda como a maior propulsora de desenvolvimento e o maior número de municípios com alto índice de desenvolvimento rural nas suas proximidades. Nela concentram-se investimentos estaduais, infraestruturas administrativas e serviços que atraem a população e geram melhores condições de vida, apesar do crescimento de áreas periféricas com moradias precárias em áreas urbanas.

Os grandes projetos levaram a descentralização econômica na geração de riqueza dentro do estado. Entretanto, essa descentralização privilegiou mais determinadas regiões do estado em detrimento de outras. Mesmo no interior das regiões marcadas pelos projetos minerais, os indicadores sociais melhoraram especialmente naqueles municípios onde se instalaram. Este comportamento dos indicadores é replicado também para o rural. Não houve uma política de regionalização dos benefícios oriundos da mineração, o que contribui para um fluxo interno dentro destas regiões em direção aos municípios mineradores.

A infraestrutura das áreas rurais dos municípios do interior do estado é mais precária de acordo com a dificuldade de acesso e grau de isolamento destas áreas. A ilha do Marajó, onde concentram os municípios com os piores índices de desenvolvimento rural, sofre com o isolamento apesar da maior proximidade geográfica com a capital. A região de Tapajós é impactada pela dificuldade de acesso, principalmente em determinadas épocas do ano, devido a precariedade da rodovia Transamazônica, cujo asfaltamento não foi concluído.

O desenvolvimento regional mostra-se um desafio para um estado das dimensões do Pará. A colonização de regiões distantes não foi acompanhada de investimentos em obras e serviços adequados ao provimento de qualidade de vida as populações tradicionais que já habitavam e aquelas que migraram com o objetivo de possuir uma pequena propriedade para cultivar. Destaca-se que o modelo de desenvolvimento adotado nas regiões de maior crescimento baseado na exploração mineral e na pecuária extensiva (atividade especializada) pode levar a um colapso das riquezas naturais em um curto espaço de tempo, o que deve ser alvo de preocupação para a implantação de políticas públicas que revertam esta tendência e garantam um presente e um futuro para a população paraense e, que os atores locais (empresários, Governo na esfera estadual e municipal, investidores etc.) diversifique as atividades econômicas do estado Pará. Considera-se importante a continuidade das análises a respeito dos indicadores de desenvolvimento rural para que seja observado se as tendências encontradas na última década estão sendo mantidas ou se sofreram alguma alteração.

\section{REFERÊNCIAS}

Abreu, I.; Nunes, J. M.; Mesias, F. Can rural development be measured? design and application of a synthetic index to portuguese municipalities. Social Indicators

Research.V. 145, 2019. Disponível em: < https://link.springer.com/article/10.1007\%2Fs11205-019-02124-w>. Acesso em: 24 nov. 2020. 
CONTERATO, M. A. Dinâmicas regionais do desenvolvimento rural e estilos de agricultura familiar: uma análise a partir do Rio Grande do Sul. Tese de Doutorado. Universidade Federal do Rio Grande do Sul. Faculdade de Ciências Econômicas. Programa de Pós-Graduação em Desenvolvimento Rural. 2008. Disponível em: $<$ http://hdl.handle.net/10183/15624>. Acesso em: 8 out. 2018.

CONTERATO, M. A.; SCHNEIDER, S.; WAQUIL, P. D. Desigualdades regionais de desenvolvimento rural do Rio Grande do Sul: uma proposta de análise multidimensional a partir de três microrregiões. Ensaios FEE, Porto Alegre, v. 30, Número Especial, p. 615-654, out. 2009. Disponível em: $<$ https://revistas.fee.tche.br/index.php/ensaios/article/view/2307/2685 >. Acesso em: 8 out. 2018.

COSTA, F, A. Pesquisa Agropecuária na Amazônia e os Fundamentos do Desenvolvimento Rural. Relatório de pesquisa, Brasília; CGEE, 2006.

COSTA, F. A. Trajetórias Tecnológicas como objeto de políticas de conhecimento para a Amazônia: uma metodologia de delineamento. Revista Brasileira de Inovação. Rio de Janeiro: FINEP, v. 8 n.1, 2009, pp.35-86.

COSTA, F. A. Mercado e produção de terras na Amazônia: avaliação aplicada a trajetórias tecnológicas. Boletim do Museu Paraense Emílio Goeldi Ciências Humanas, v. 5, 2010, pp. 25-39.

COSTA, F.A.; FERNANDES, D.A. Dinâmica agrária, Instituições e Governança Territorial para o desenvolvimento sustentável da Amazônia. Revista de Economia Contemporânea, v. 20, n.3, 2016, pp. 517-552.

DELGADO, G. C. Expansão e modernização do setor agropecuário no pós-guerra: um estudo da reflexão agrária. Estudos avançados, v. 15, n. 43, p. 157-172, 2001. Disponível em: <http://www.scielo.br/scielo.php?script=sci_arttext\&pid=S0103$40142001000300013>$. Acesso em: 8 out. 2018.

HAIR JR., J. F. et al. Análise multivariada de dados. 5 ed. Porto Alegre: Bookman, 2005. $593 \mathrm{p}$.

HURTIENNE, T. P. Agricultura familiar e desenvolvimento rural sustentável na Amazônia. Novos Cadernos NAEA, v. 8, n. 1 - p. 019-071 jun. 2005. Disponível em: <http://www.periodicos.ufpa.br/index.php/ncn/article/view/47>. Acesso em: 16 out. 2018.

INSTITUTO BRASILEIRO DE GEOGRAFIA E ESTATÍSTICA. Censo Demográfico. Brasília 2006. Disponível em: <https://sidra.ibge.gov.br>. Acesso em: 10 nov. 2017.

Censo Agropecuário. Brasília 2010. Disponível em:

<https://sidra.ibge.gov.br>. Acesso em: 10 nov. 2017. 
Portal de Mapas. Disponível em:

<https://portaldemapas.ibge.gov.br/portal.php\#homepage $>$. Acesso em: 20 nov. 2018.

KAGEYAMA, A. Desenvolvimento rural: conceito e medida. Cadernos de Ciência \& Tecnologia, v. 21, n. 3, p. 379-408, 2004. Disponível em:

<https://seer.sct.embrapa.br/index.php/cct/article/view/8702>. Acesso em: 4 abr. 2018.

Desenvolvimento rural: conceitos e aplicação no caso brasileiro. Porto Alegre: Editora da UFRGS, 2008. 240p.

Hashemi, N. Gholamreza, G. A proposed sustainable rural development index (SRDI): lessonsfrom Hajij village, Iran. Tourism Management. v. 59, abr, 2017. Disponível em: < https://doi.org/10.1016/j.tourman.2016.07.021>. Acesso em: 22 nov. 2020.

LOBÃO, M. S; STADUTO, J. Desenvolvimento rural na amazônia brasileira: níveis e distribuição regional na década 2000. Ambient. soc. [online]. 2020, vol.23 Disponível em:<http://www.scielo.br/scielo.php?script=sci_arttext\&pid=S1414753X2020000100311\&lng=pt\&nrm=iso $>$. Acesso em: 25 nov. 2020.

MICHALEK, J.; ZARNEKOW, N. Application of the Rural Development Index to analysis of rural regions in Poland and Slovakia. Social Indicators Research,105(1), 137. 2012 Disponível em:<https://doi.org/10.1007/s11205-010-9765-6> .Acesso em: 25 nov. 2020.

MELO, C. O.; PARRÉ, J. L. Índice de desenvolvimento rural dos municípios paranaenses: determinantes e hierarquização. Revista de Economia e Sociologia Rural, v. 45, n. 2, p. 329-365, 2007. Disponível em: <https://ageconsearch.umn.edu/bitstream/161395/2/05.pdf>. Acesso em: 8 out. 2018.

MELO, R. F. de. Análise do desenvolvimento rural na região do Triângulo Mineiro e Alto Paranaíba: caracterização dos municípios com base em indicadores populacionais, econômicos, ambientais e de bem-estar social. Dissertação (Mestrado). Universidade Federal de Uberlândia. Instituto de Economia. Programa de Pós-Graduação em Economia Uberlândia, MG. 2005. Disponível em: <http://www.ppge.ie.ufu.br/node/91>. Acesso em: 8 out. 2018.

MINGOTI, S. A. Análise de dados através de métodos de estatística multivariada: uma abordagem aplicada. Belo Horizonte: Editora UFMG, 2005. 297 p.

NAVARRO, Z. Desenvolvimento rural no Brasil: os limites do passado e os caminhos do futuro. Estudos avançados, v. 15, n. 43, p. 83-100, 2001. Disponível em:

$<$ http://www.scielo.br/scielo.php?script=sci_arttext\&pid=S0103-

$40142001000300009>$. Acesso em: 16 out. 2018. 
OLIVEIRA, N. M.; PIFFER, Moacir. Conjuntura do desenvolvimento regional dos municípios do estado do Tocantins. Desenvolvimento Regional em debate, v. 6, n. 3, p. 32-61, 2016. Disponível em: <https://dialnet.unirioja.es/servlet/articulo?codigo=5733091>. Acesso em: 04 mai. 2018.

OLIVEIRA, N. M.; PIFFER, M. Determinantes do Perfil Locacional das atividades produtivas no Estado do Tocantins. Boletim de Geografia (UEM), v. 36, p. 92-111, 2018. Disponível em: <: http://www.periodicos.uem.br/ojs/index.php/BolGeogr/article/view/34044>. Acesso em 05 ago. 2018. DOI: http://dx.doi.org/10.4025/bolgeogr.v36i1.34044 PARÁ. Atlas de Integração Regional do Estado do Pará. Belém, PA: Secretaria de Estado de Integração Regional, 2010. 347p.

PROGRAMA DAS NAÇÕES UNIDAS PARA O DESENVOLVIMENTO. Atlas do Desenvolvimento Humano no Brasil. 2013. Disponível em: <http://atlasbrasil.org.br/2013>. Acesso em: 10 nov. 2018.

RENZI, Adriano. A ruralidade e o desenvolvimento econômico local: o caso dosmunicípios brasileiros.2020. 264f.Tese (Doutorado em Desenvolvimento Regional e Agronegócio) -UNIOESTE, Toledo, 2020.

RODRIGUES, R. Trabalhadores na produção da essência de pau rosa na Amazônia. Novos Cadernos NAEA, v. 19, n. 2, 2016. Disponível em:

<https://periodicos.ufpa.br/index.php/ncn/article/viewFile/2197/3920>. Acesso em: 04 ago. 2018.

SANTOS, N. C. A. dos. Indicador de desenvolvimento rural para as regiões de integração do estado do Pará. Dissertação (Mestrado) - Universidade Federal do Bahia. Faculdade de Economia. Programa de Pós-Graduação em Economia. Salvador. 2016. Disponível em: <https://repositorio.ufba.br/ri/handle/ri/18716>. Acesso em: 30 ago. 2018.

SCHNEIDER, S. et al. A abordagem territorial do desenvolvimento rural e suas articulações externas. Sociologias, v. 6, n. 11, 2004. Disponível em: <http://www.scielo.br/pdf/soc/n11/n11a06 >. Acesso em: 16 out. 2018.

SEN, A. Desenvolvimento como liberdade. São Paulo: Companhia das Letras, 2000. 409p.

SILVA, J. G. da. O Novo Rural Brasileiro. Revista Nova economia, Belo horizonte. 7(1):43-81, mai. 1997. Disponível em:

<http://revistas.face.ufmg.br/index.php/novaeconomia/article/view/2253/1193>. Acesso em: 16 out. 2018.

SILVA, L. J. M. da. A relação entre crescimento econômico e desenvolvimento sustentável: a Região do Araguaia no contexto regional paraense. 2012. 229 f. Tese (Doutorado) - Universidade Federal do Pará, Núcleo de Altos Estudos Amazônicos. 
Belém, 2012. Programa de Pós-Graduação em Desenvolvimento Sustentável do Trópico Úmido. Disponível em: <http://repositorio.ufpa.br/jspui/handle/2011/2963>. Acesso em: 15 ago. 2018.

SILVA, et. al. Índice de Sustentabilidade dos Municípios da Amazônia (ISMA): metodologia para os cálculos dos indicadores. Incubadora de Políticas Públicas da Amazônia. Núcleo de Altos Estudos Amazônicos/NAEA-UFPA, 2017.

SOUZA, P. L. R. Desenvolvimento rural no contexto amazônico: uma análise multidimensional do estado do Pará. 2014. 91f. Dissertação (Mestrado). Pontifícia Universidade Católica do Rio Grande do Sul, Porto Alegre.

STEGE, A. L.; PARRÉ, J. L. Desenvolvimento rural nas microrregiões do Brasil: um estudo multidimensional. Revista Teoria e Evidência Econômica, v. 17, n. 37, 2011. Disponível em: <http://seer.upf.br/index.php/rtee/article/view/4227>. Acesso em: 16 ago. 2018.

PLOEG, VAN DER J. D. et al. Rural development: from practices and policies towards theory. Sociologia Ruralis, Oxford, v. 40, n. 4, p. 391-408, out. 2000. Disponível em: $<$ https://onlinelibrary.wiley.com/doi/epdf/10.1111/1467-9523.00156>. Acesso em: 05 jun. 2018.

VEIGA, J. E. da. A face rural do desenvolvimento: natureza, território e agricultura. Porto Alegre: Editora da UFRGS, 2000.197 p.

VEIGA, J. E. da. O Brasil rural ainda não encontrou seu eixo de desenvolvimento. Estudos Avançados, São Paulo, v. 15, n. 43, p. 101-119, set./dez. 2001. Disponível em: <http://www.scielo.br/pdf/ea/v15n43/v15n43a10.pdf > Acesso em: 15 jun. 2018.

WANDERLEY, M. de N. B. A emergência de uma nova ruralidade nas sociedades modernas avançadas-O "rural" como espaço singular e ator coletivo. Estudos sociedade e agricultura, n. 15, out. 2000, pp.87-145. Disponível em: <http://r1.ufrrj.br/esa/V2/ojs/index.php/esa/article/view/178>. Acesso em: 16 out. 2018.

WAQUIL, P. et al. Avaliação de desenvolvimento territorial em quatro territórios rurais no Brasil. Redes, v. 15, n. 1, pp.104-127, 2010. Disponível em: <http://www8.ufrgs.br/ppge/pcientifica/2007_04.pdf>. Acesso em: 29 ago. 2018.

Adriano Nascimento Paixão. Doutor em Economia Aplicada. Universidade Federal da Paraiba -UFPB. Professor do Programa de Pós-graduação em Desenvolvimento Regional (PPGDR/UFT). Email:

Nilton Marques Oliveira. Economista pela UEM, Mestre em Economia Aplicada pela UFV e Doutor em Desenvolvimento Regional e Agronegócio pela UNIOESTE, Toledo - PR. Professor do Programa de Pós-graduação em Desenvolvimento Regional e do curso de Ciências Econômica da Universidade 
Federal do Tocantins - UFT. Lider do Grupo de Pesquisa em Desenvolvimento Regional e Territorial do Centro Norte do Brasil (DRT - Centro Norte). Email:

Marcus Vinicius Mendonça. Mestre em Desenvolvimento Regional. Instituto Chico Mendes de Conservação da Biodiversidade (ICMBIO). Analista Ambiental. Email:

Rodolfo Alves Luz. Doutor em Geografia Física. Universidade Federal do Tocantins. Professor do Programa de Pós-graduação em Desenvolvimento Regional (PPGDR/UFT).

Como citar: PAIXÃO, Adriano Nascimento et al. Desenvolvimento Rural dos Municípios do Estado do Pará: desigualdade e espacialidade. Redes (St. Cruz Sul, Online), Santa Cruz do Sul, v. $25, \quad$ p. 1504-1527, nov. 2020. ISSN 1982-6745. doi:https://doi.org/10.17058/redes.v25i0.15171.

\section{CONTRIBUIÇÃO DE CADA AUTOR}

a. Fundamentação teórico-conceitual e problematização: Mendonça; Paixão; Oliveira; Luz.

b. Pesquisa de dados e análise estatística: Mendonça; Paixão; Oliveira; Luz.

c. Elaboração de figuras e tabelas: Mendonça; Paixão; Oliveira; Luz.

d. Fotos: não se aplica.

e. Elaboração e redação do texto: Mendonça; Paixão; Oliveira; Luz.

f. Seleção das referências bibliográficas: Mendonça; Paixão; Oliveira; Luz.

Fontes de financiamento: Instituto Chico Mendes de Conservação da Biodiversidade (ICMBIO). 